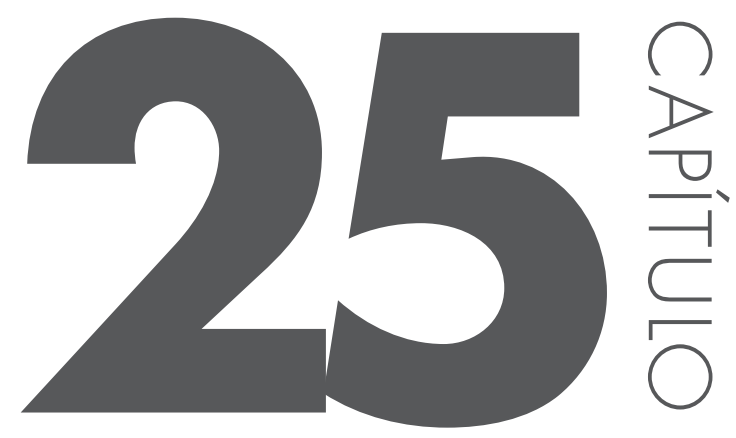

\title{
ASPECTOS LÉXICO-CULTURAIS EM MANUSCRITOS GOIANOS: PERCURSOS DE PESQUISA
}

Xavier, Vanessa Regina Duarte ${ }^{1 *}$; Paula, Maria Helena de ${ }^{2}$

' UFG/Regional Jataí; Pós-Doutoranda PMEL/UFG/Regional Catalão

2 UAELL; PMEL/UFG/Regional Catalão

*email:vrdxavier@gmail.com

\section{RESUMO}

O presente texto tem por objetivo revisitar nossas experiências de pesquisa, da graduação ao pós-doutorado, com vistas a demonstrar a convergência teóricometodológica entre elas. Nesse sentido, cumpre dizer que as três pesquisas realizadas até o momento, a saber, uma de iniciação científica, outra de doutorado e a atual, de pós-doutorado, têm em comum o fato de ampararem-se na edição semidiplomática de manuscritos goianos, com o intuito de inventariar o léxico e analisá-lo em sua relação com a História e a cultura goiana. Os primeiros documentos editados eram termos de praça de Catalão e datavam das primeiras décadas do século XX. Os segundos eram cartas trocadas entre o 
governador da Capitania de Goiás e o rei D. José I, em sua maioria, e datavam de Vila Boa de Goiás, do século XVIII; e os últimos são registros de óbitos de Santa Luzia de Goiás, de 1786 a 1789. Em que pesem estas dissonâncias, as pesquisas convergem na linha temática, vale dizer, a intersecção entre os estudos lexicais e aspectos socioculturais, em diferentes nuances, no tratamento dos dados, assentado nas perspectivas filológica e lexical, e na matéria documental goiana.

Palavras-chave: Léxico; Cultura goiana; Filologia. 


\section{DEFININDO O CURSO DO TEXTO: BREVES PALAVRAS}

A reflexão sobre nossos percursos de pesquisa nos campos da Filologia e da Lexicologia tem por objetivo preconizar a abordagem léxico-cultural de manuscritos goianos, demonstrando alguns dos resultados por nós alcançados até o presente por meio dela. $\mathrm{Na}$ primeira parte do texto, consta uma breve discussão sobre os corpora, as metodologias, as linhas temáticas e os principais resultados da pesquisa de iniciação científica realizada durante a graduação em Letras-Português (UFG/Regional Catalão) e vinculada ao Programa Institucional Voluntário de Iniciação Científica (PIVIC) do CNPq, e da pesquisa de doutorado, desenvolvida no âmbito do Programa de Pós-Graduação em Filologia e Língua Portuguesa (USP), com o financiamento da Fundação de Amparo à Pesquisa do Estado de São Paulo (FAPESP).

Em um segundo momento, expõe-se sobre a pesquisa atualmente desenvolvida no estágio pós-doutoral, ligada ao Programa Nacional de PósDoutorado (PNPD/Capes), em parceria com o Programa de Mestrado em Estudos da Linguagem (PMEL - UFG/Regional Catalão). Nesta parte do texto, dar-se-ão a conhecer, de igual maneira, os objetivos, o corpus, a metodologia, a linha temática e alguns resultados da pesquisa.

Nesse sentido, o texto assenta-se na perspectiva lexical em sintonia com a cultura e a História, partindo de uma compreensão ampla do léxico como o repertório vocabular de uma língua, que abrange, portanto, o conjunto total das suas denominações. Nesse sentido, Câmara (2010, p. 46) pontua que: "Considerados os diferentes níveis de uma língua, o lexical apresenta-se, sem dúvida, como a porta mais aberta na relação entre as várias culturas existentes [...]”. Em vista disso, o léxico desponta como um objeto de investigação, por excelência, dinâmico e multidisciplinar, porque demanda a consideração de outras esferas do conhecimento linguístico, como a Fonologia, a Sintaxe, a Análise do Discurso, a Filosofia, a História etc.

Face a isto, parece relevante fazer um estudo de perspectiva lexical levando em consideração a sua interface com as disciplinas mencionadas anteriormente. Tem constituído o foco do nosso interesse, ao longo da trajetória de pesquisa aqui esboçada, o léxico de épocas pretéritas, a fim de caracterizar o estado de língua em dada sincronia, com as suas nuances semânticas, sintáticas e discursivas.

Nesse sentido, é nosso intento analisar o léxico de manuscritos de épocas distanciadas do presente, em virtude da escassez de estudos desta natureza em Goiás e do fato de haver demasiada documentação em vias de deterioração na 
região, em que pese a sua grande relevância para a compreensão da sociedade e cultura goianas. Mostra-se, pois, urgente digitalizar e analisar fontes escritas antigas do léxico goiano, de modo a contribuir com o estudo da história da língua portuguesa através de algumas das suas variedades regionais.

Para a constituição de fontes fidedignas à abordagem referida, recorremos ao aparato teórico-metodológico da Filologia, disciplina que tem se dedicado incansavelmente a esta tarefa, aprimorando-se constantemente para atender às demandas que surgem. Com frequência, temos adentrado, ainda, no terreno da Lexicografia, com vistas a elucidar os contornos léxico-semânticos dos itens lexicais.

Cumpre, pois, delinear, em breves considerações, nossos percursos de pesquisa, da graduação ao pós-doutorado, avaliando os passos dados e as “pedras" do caminho. O que se propõe, portanto, é abordar os meandros da pesquisa acadêmica, em seus sabores e dissabores, com base em um caminho repleto de estradas e veredas filológico-lexicais.

\section{REVISITANDO NOSSAS TRAJETÓRIAS DE PESQUISA}

O filólogo sente-se desafiado a desvendar o traçado das letras em manuscritos antigos e é movido pelo fascínio diante de aspectos linguísticos e socioculturais que neles se revelam. Esta assertiva parece explicar o fato de que, embora a disciplina Filologia não integrasse a grade curricular do Curso de Letras à época, a possibilidade de fazer uma pesquisa nesta área, quando eu me encontrava no $6^{\circ}$ período do curso referido, em 2006, tenha sido tão instigante para mim. Assim, teve início a minha trajetória como pesquisadora.

A pesquisa de Iniciação Científica (doravante IC) intitulou-se "Estudo lexical das categorias verbo, substantivo e adjetivo no ' 2 ' Livro dos Registros de Termos de Praça de Catalão" e vinculava-se ao projeto "Formação de corpora escritos de Goiás - leitura e edição de manuscritos”, também coordenado pela Profa. Dra. Maria Helena de Paula. Em virtude da participação neste último, realizamos a digitalização de documentos cartoriais, bem como a organização dos arquivos obtidos, a preparação e execução de oficinas, minicursos e/ou palestras sobre o tema do projeto e auxiliamos na edição de documentos do acervo. A atuação neste projeto findou em 2012, devido ao seu término.

$\mathrm{Na}$ pesquisa de IC supracitada, o corpus compôs-se de 13 fólios (escritos em recto e verso), contendo termos de praça referentes a animais leiloados em praça pública, no paço da Intendência de Catalão, no início do século XX. 
Tais termos eram essencialmente descritivos, mencionando e caracterizando os procedimentos tomados no decorrer das transações, os animais levados a leilão, os arrematantes, as quantias pagas, os funcionários que participavam dos eventos, as datas e locais em que estes ocorriam, como mostra o excerto abaixo:

||1 v.ll Termo de Praça | Aos 19 dias do mēz de Fevereiro do anno de 1902, I nesta Cidade de Catalaõ, no largo do Paço Munici- I pal, ahi presentes o Intendente Major Paulino Ribeiro I Guimaraẽs commigo Secretario do mesmo, o I Procurador José Alvares da Silveira Machado e o I Porteiro Illydio Landim precedidas as formalida- I des legaes, foram levados em praça publica e de accor- I do com o edital os animaes seguintes: [espaço] I 1 Egua queimada pedrez regulando 5 annos com as se- I guintes marcas: R. FB. arrematada por $40 \$ 000$ reis pelo I Senhor Antonio Alves Fragozo. [espaço] I 1 Cavallo russo grande, regulando 9 annos com as I seguintes marcas: YC, JV e 72, arrematado por I 45500 reis pelo Senhor Domingos Bispo (LTP - Livro dos Registros de Termos de Praça de Catalão).

Segundo Harris (2006), a Filologia requer uma leitura atenta e minuciosa do texto, não se presta a uma passada de olhos, quase que instantânea; demanda uma entrega por parte do leitor e uma observação acurada. Isso pode ser inferido pelo trecho acima, em que o termo foi editado semidiplomaticamente e em formato justalinear, preservando-se as características gráficas e a disposição das linhas dos originais. A opção pela edição semidiplomática em todas as pesquisas realizadas até o momento deve-se ao fato de ela admitir interferências do editor, sempre assinaladas, com vistas a facilitar a leitura do texto, ao passo que conserva suas principais propriedades.

Dentre as contribuições da Filologia, Harris diz que

a cuidadosa leitura de textos obscuros e por vezes inescrutáveis, palavra por palavra, hora após hora, cria o tipo de técnica de leitura atenta (...). Aprendemos a fazer uma leitura superficial do crescente número de materiais escritos em nossa sociedade, que os coleciona, especialmente hoje em dia, com a Internet (2006, p. 141).

Nesse sentido, a Filologia parece estar na contramão das leituras superficiais e rápidas propiciadas pelo uso de ferramentas tecnológicas cada vez mais avançadas. A edição, que transpõe o texto manuscrito para caracteres 
informatizados, requer uma observação detalhada sobre o estilo de escrita do escriba e suas idiossincrasias e possíveis lapsos de memória. Do contrário, corre-se o risco de fazer inferências equivocadas acerca do hábito de escrita de uma dada época.

É interessante notar que o intendente, que correspondia à função do prefeito naquela época, participava destes eventos, que ocorriam no paço da Intendência, o que demonstra a sua relevância para a esfera econômica local, evidenciando, inclusive, um de seus mais significativos ramos, a saber, a pecuária.

Podemos, ainda, esboçar considerações sobre algumas lexias extraídas do excerto disposto supra, cujos sentidos podem revelar-se inusitados, sobretudo àqueles que pouco sabem sobre a criação de animais, especialmente, de equinos e bovinos. Nesse sentido, uma "Egua queimada pedrez" diz respeito à fêmea do cavalo, com a coloração do pelo "Tirante a negro pela acção do calor, tostado, escuro" (CALDAS AULETE, 1881, p. 1451) e, ainda, "Salpicado de preto e branco", conforme a definição constante em Figueiredo (1925, p. 330) para a lexia pedrês.

Por seu turno, o sintagma "Cavallo russo" refere-se a um animal doméstico da família dos equídeos, cujo pelo é "pardo claro; que tem mistura de pelos brancos e pretos” (CALDAS AULETE, 1881, p. 1581). Um olhar mais atento revela, ainda, que a lexia praça, no fragmento em análise, foi empregada com duas acepções distintas, ou seja, de venda ou arrematação, no caso do sintagma “Termo de praça”, e de lugar público, aberto, no excerto "foram levados em praça publica".

Outra lexia digna de nota é o verbo regular, que foi utilizado no fragmento acima com a acepção de "Aparentar, dar idéia de ter ou ser ou estar mais ou menos”, segundo a definição de Ortêncio (1983, p. 378), o que coaduna com o fato de a idade dos animais não ser informada precisamente, mas de forma aproximada.

Elaboraram-se, ainda, vocabulários de frequência para as categorias lexicais e para os antropônimos, contendo a frequência e a localização de cada ocorrência no material editado. $\mathrm{Na}$ sequência, os itens lexicais mencionados foram analisados segundo a sua frequência no texto, obtendose os seus campos semânticos mais recorrentes, quais sejam: profissões, animais, partes do corpo dos animais, coloração da pelagem, espaço, tempo, condições materiais e físicas do texto, procedimentos formais do seu registro escrito e valores monetários (XAVIER, 2008, p. 218-219).

A última etapa consistiu na organização de um Glossário de Manuscritos Goianos, com base na consulta aos dicionários de Caldas Aulete (1881), 
Figueiredo (1925) e Ortêncio (1983), e na verificação das acepções em processo de arcaização ou mudança semântica.

Em 2008, ingressei no Programa de Pós-Graduação em Filologia e Língua Portuguesa da Universidade de São Paulo como aluna de mestrado, desenvolvendo um projeto que visava ao estudo filológico-lexical de documentos goianos do século XVIII. Os manuscritos que constituíram o corpus da pesquisa pertenciam ao "Livro para servir no registro do caminho novo de Parati - Thomé Ignácio da Costa Mascarenhas (1724-1762)”, que conta com 221 fólios no total e se acha disponível no Arquivo Estadual de Goiás. Nele, selecionaram-se 73 fólios (escritos em recto e verso), de 1751 a 1753, para a edição e análise lexical.

A temática dos documentos revelou-se diversificada, abordando questões como a cobrança de tributos sobre o ouro e outros minerais preciosos, a falta de moedas para o comércio, a escassez de religiosos com boa índole dispostos a aldear e catequizar os índios, os castigos severos impostos por muitos religiosos aos habitantes nativos do território goiano, a insuficiência de militares na região, a contratação de capitães e/ou coronéis para aprisionar e domesticar os índios por parte do governo e, por vezes, dos próprios moradores.

Em 2010, no exame de qualificação, a pesquisa de mestrado converteuse em uma pesquisa de doutorado, conforme indicação feita pela banca. A tese resultante intitulou-se "Conexões léxico-culturais sobre as minas goianas setecentistas no 'Livro para servir no registro do caminho novo de Parati" " e teve como objetivo central evidenciar as inter-relações entre léxico e cultura, com base em manuscritos do século XVIII. Com esse intuito, esta investigação pautou-se pela estruturação e análise dos campos lexicais mais representativos dos assuntos abordados no corpus, correlacionando-os ao contexto social, histórico e cultural da época. Antes, porém, os manuscritos foram editados semidiplomaticamente, a fim de assegurar a sua confiabilidade para a análise lexical, bem como para outros estudos linguísticos.

$\mathrm{Na}$ pesquisa de doutorado, as palavras ditas "lexicais", a saber, os substantivos, adjetivos e verbos, também foram inventariados e constituíram um Índice de Frequência e de Ocorrências dos Itens Lexicais, contendo, respectivamente, o número de ocorrências de cada item lexical no corpus, a indicação das linhas da edição nas quais elas constam e as formas variantes no nível ortográfico e gramatical, como ilustra o verbete na sequência: 


\section{Quadro 1 - Verbete ilustrativo do Índice de Frequência e de Ocorrências dos Itens Lexicais.}

\section{[precatório] adj. (2) preCatorias (1) 2660, precatorias (1) 816, s. (1) precatorios (1) 4400}

Fonte: Xavier (2012).

Nesse sentido, tanto os Vocabulários de Frequência, quanto o índice referido são instrumentos lexicográficos que permitiram o levantamento quantitativo dos dados lexicais nos corpora e o posterior tratamento qualitativo destes. Constituíram, portanto, formas de sistematizar os dados e possibilitar a sua rápida contextualização.

Cumpre ressaltar que a consulta dos itens lexicais em obras lexicográficas de épocas coetâneas e contemporâneas aos documentos também foi efetuada em nossa pesquisa de doutoramento, haja vista a necessidade de elucidar os sentidos por eles assumidos no co-texto, além de facilitar o estabelecimento das relações semânticas entre as lexias no interior dos campos lexicais. As obras consultadas foram o "Vocabulario portuguez \& latino", de Bluteau (1712-1728), o “Diccionario da língua portugueza”, de Moraes Silva (1813), o "Dicionário Houaiss da língua portuguesa", de Houaiss e Villar (2001), e o "Novo dicionário eletrônico Aurélio", de Ferreira (2004), englobando o período imediatamente anterior à datação dos documentos e algumas das obras consideradas como thesaurus da Lexicografia contemporânea.

No fragmento da edição disposto a seguir, a saber: "Ordenou VossaMagestade I ao Governador que no cazo de necessidade déssemos officiaes da I Camera boletos, quando de outraSorte Se naõ podece dar outro I remedio" (LR, 76v.); é digna de nota a lexia boleto, que referese a um documento que impunha aos moradores da Capitania goiana a obrigação de abrigar e alimentar os soldados que ali serviam, devido à falta de quartéis na região. Nesse, como em vários outros casos, a consulta a obras lexicográficas da época fez-se essencial no sentido de esclarecer os sentidos das lexias no contexto de uso, já que é um uso marcado por uma necessidade social, que hoje não existe mais, embora o signo permaneça com outras acepções.

De igual maneira, a lexia bando, no excerto "No tempo emquetomey posse destegoverno, man I dey que emtudo oquepertencia ao Contráto dos Diamantes I deRio claro, Se déce áexecuçaõ todas as ordens, Bandos, e I mais providencias, quehavia tomado oGovernador Gomes Freyre I deAndrada" (LR, 69r.), tornou necessária a consulta aos dicionários referidos, elucidando- 
se o seu sentido de espécie documental, de natureza informativa, afixado em local público, contendo uma ordem advinda de uma autoridade pública.

A esse respeito, vale assinalar que estava entre as pretensões da nossa pesquisa de doutoramento a elaboração de um glossário a partir do inventário lexical do corpus. Contudo, em vista da extensão excessiva que a tese assumiria, conforme a banca avaliadora da tese apontou no momento da qualificação, optamos por retirá-lo. Apesar disso, grande parte das acepções que o constituiu se fez presente no momento da análise dos campos lexicais.

No caso da pesquisa de IC, podem-se elencar, a título de demonstração dos resultados obtidos, o adjetivo argolado e a locução adjetiva de carro, pois ambos se correlacionam a um aspecto comum das cidades goianas até o início do século XX, a saber, o uso de carros-de-bois como veículo de transporte de carga e de pessoas, de modo geral. De acordo com Nogueira (1980), o seu uso perdurou mesmo após o surgimento dos automóveis devido aos baixos custos de manutenção e à valorização dos bois. Disso depreende-se que esta caracterização se fazia relevante ao leilão dos animais, porque os bois utilizados em carros-de-bois eram mais valorizados, por serem corpulentos e dóceis em geral.

No que tange aos itens lexicais mais recorrentes no $2^{\circ}$ Livro dos Registros de Termos de Praça de Catalão, i. e., o adjetivo arrematado (72 ocorrências) e o substantivo marca (65 ocorrências), convém dizer que o primeiro revela o propósito do evento registrado, que é o arremate de animais pela maior quantia ofertada, e o segundo um dos aspectos em que os animais são descritos, porque os identificam, ou seja, a marca feita por um instrumento de ferro em brasa contendo as letras iniciais do seu dono, geralmente na região lombar do animal.

Por sua vez, na análise da frequência dos itens lexicais na pesquisa de doutorado, observou-se que, na classe dos substantivos, os mais recorrentes foram ouro (339 ocorrências) e mina (233 ocorrências). Ambos se vinculam a um dos temas centrais do corpus, a exploração aurífera, que foi responsável pela expressiva prosperidade da Capitania goiana na época. Ademais, a própria formação da Capitania e, consequentemente, o seu povoamento, estiveram ligados à descoberta do ouro na região, que durante muito tempo foi a principal atividade econômica local. Sobre o item mina, é mister assinalar que diz respeito ao local onde os minérios se encontram na natureza e, por conseguinte, onde se formaram os primeiros povoados goianos.

Por outro prisma, a organização das lexias inventariadas nesta pesquisa em campos lexicais decorreu do fato de o corpus apresentar temáticas variadas. Desse modo, seria possível obter uma representação geral dos assuntos por ele abordados e da estruturação dos itens lexicais no interior dos campos. Obtivemos 
um total de 16 campos, os quais receberam as seguintes designações: Etnia, Aspecto da terra, Metais e minerais, Vias de comunicação, Espaço, Doenças e enfermidades, Autoridades eclesiásticas, Ofícios e profissões, Tributação, Moedas, Transações econômicas, Pesos e medidas, Corpo militar, Crimes e delitos, Procedimentos jurídicos e Documentos.

Para exemplificar a distribuição das lexias em campos conforme as relações semânticas entre elas, selecionamos o campo lexical "Pesos e medidas", o qual compôs-se das lexias arroba, grão, légua, marco, medida, oitava, onça e peso, sendo os itens lexicais peso e medida sinônimos entre si e hiperônimos das lexias arroba, grão, marco, oitava e onça. Por sua vez, a lexia medida também é hiperônima de légua, usada para indicar a distância entre os arraiais. Tais lexias foram empregadas no corpus para indicar o peso do ouro extraído, com vistas à sua tributação, e também aquele extraviado ou contrabandeado nas minas. Era comum usar tais lexias igualmente como unidades monetárias em situações de negociação, o que se devia à falta de moedas na região.

Parece pertinente exemplificar um pouco mais as relações de sentido estabelecidas entre as lexias, tal como entre condutor e comboieiro, em que aquele é o hiperônimo deste, como se percebe no quadro abaixo, contendo as acepções de ambas:

Quadro 2 - Cotejo de acepções das lexias condutor e comboieiro.

\begin{tabular}{cc}
\hline LEXIA & ACEPCC̃̃o \\
\hline Condutor & "0 que conduz, guia" (MORAES SIILVA, 1813, p. 1440). \\
\hline Comboieiro & $\begin{array}{c}\text { "De terra, o que dirige o comboi das Tropas, ou } \\
\text { recovages das Minas do Brasil para os Portos do } \\
\text { Mar, \& c." (MORAES SILVA, 1813, p. 417). }\end{array}$ \\
\hline
\end{tabular}

Fonte: Xavier (2012).

Observa-se, pelo exposto, que o item lexical condutor possui uma acepção mais geral, enquanto o segundo apresenta um sentido mais específico, vale dizer, de condutor de animais, assim como de pessoas e mercadorias. Configura-se, assim, a hiperonímia entre as lexias, assente na relação hierárquica entre elas, em que a primeira abarca e inclui o sentido da segunda, tal como pontua Dubois et. al. (1997). 


\section{APONTAMENTOS GERAIS SOBRE A PESQUISA ATUAL}

O pós-doutorado realizado nesta instituição, com o projeto intitulado "Rituais post-mortem no Goiás setecentista: edição e estudo lexical de registros da Matriz de Santa Luzia", teve início em setembro do ano passado, sob a supervisão da Profa. Dra. Maria Helena de Paula e se vincula ao projeto "Em busca da memória perdida: estudos sobre a escravidão em Goiás” (FAPEG), também coordenado por ela.

O presente estudo envereda-se pelos campos filológico, diplomático e lexical, no intuito de caracterizar aspectos socioculturais relacionados à escravidão em Goiás, matizados no léxico inventariado em manuscritos do "Livro de Óbitos 01" de Luziânia-GO, sendo que os registros selecionados para a pesquisa datam do período de 1786 a 1789. Metodologicamente, a pesquisa se assenta na edição semidiplomática dos fólios, assim como no inventário e na análise lexical destes.

O livro referido é composto por registros de óbitos feitos pela paróquia de Santa Luzia-GO de 1786 a 1814, os quais informam o nome da pessoa que faleceu, a data, os sacramentos recebidos e o modo e lugar em que foi sepultada e, quando se trata de escravo, geralmente incluem-se a nação a que pertencia e o nome do seu dono. É o que ilustra o fragmento abaixo:

Emoprimeirodia domes deMarço doanno demil setecentos, e I oitenta, eoito faleceo davidaprezente Comos Sacramentos da I Penitencia, eExtrema=Vnçaó [o] adulto Francisco Angola escra | vo do Capitaõ Fernando Nogueira soares Falcaõ: foi enco= | mendado, enodia dous Sepultado noAdro desta Matris deSanta I Luzia, eSanto Antonio daComarca deGoyaz; epara Constar fiz I esteassento// O Vigario TimotheoCorrea deToledo (fl. 13 r.).

Os objetivos da pesquisa atual são: i) constituir fonte fidedigna aos estudos sobre a história do português do Brasil, bem como aos de ordem histórica, antropológica, paleográfica, dentre outros; ii) compor um acervo lexical acerca da escravidão no centro-oeste brasileiro; iii) conceituar diplomaticamente o termo de registro de óbito; iv) inventariar e analisar o vocabulário mais recorrente no corpus; v) fortalecer as pesquisas no campo da Filologia e da Lexicologia na região centro-oeste do Brasil.

Merece registro a influência da instituição responsável pelos registros referidos, a saber, a Igreja Católica, sobre os elementos que são nele 
mencionados, como: os sacramentos recebidos pela pessoa falecida, a Penitencia e a Extrema=Vnçaó; o fato de ter sido encomendado, ou seja, de se ter rogado a Deus por sua alma; o seu sepultamento no Adro da Matris de Santa Luzia e Santo Antônio da Comarca de Goiás, vale dizer, nos arredores ou na parte externa da igreja. Corrobora isto o fato de um vigário ter assinado o registro.

Ademais, a concepção predominante à época sobre a morte sofria influências do catolicismo, inspirando temor aos portugueses e africanos, de modo geral, no período colonial, devido à imagem macabra formulada em torno do Juízo Final, como o julgamento dos bons e maus, do que dependia o seu destino final. Imperava a crença em uma vida mais plena e feliz após a morte, que era uma morte somente em termos, porque se morria da vida terrena para renascer para a vida eterna.

Todavia, a passagem para esta segunda vida se condicionava à salvação das almas. Por isso, as pessoas de modo geral, de quaisquer raças ou crenças, cuja morte fosse presumida, deveriam recebessem os sacramentos cristãos, como o da Penitência, vinculado ao arrependimento pelos pecados cometidos.

Lacet (2003), analisando os rituais de morte de escravos e libertos de Vila Rica no século XVIII, considera os sacramentos como sendo de suma importância para uma "boa morte", tendo especial destaque o da extremaunção ou unção dos enfermos, haja vista que

A extrema-unção, tanto para a população livre como para a população cativa, era um sacramento, por excelência, purificador, que, paradoxalmente, preparava a entrada do cristão no além e, ao mesmo tempo, podia exercer um efeito de restaurar a saúde debilitada dos doentes (LACET, 2003, p. 28).

Em que pese o fato de o sacramento da extrema-unção também se destinar ao restabelecimento da saúde do indivíduo que padece de algum mal físico grave, é frequentemente ministrado às pessoas já bastante debilitadas fisicamente e cuja morte é esperada para breve. Em vista disso, tal sacramento é associado, não raras vezes, a situações de morte, embora não tenha, em sua essência, este fim. Revelou-se bastante incidente a menção a este sacramento no corpus da pesquisa e, conquanto ainda não tenhamos dados quantitativos precisos que demonstrem este fato, conjectura-se que este sacramento, juntamente com o da Penitência, estejam entre os mais mencionados nos registros de óbitos.

Ainda em consonância com as "Constituições primeiras do arcebispado da Bahia”, citadas por Lacet (2003, p. 29), a extrema-unção é concedida com vistas a perdoar as faltas do moribundo, promover o consolo do enfermo, com 
a cura do seu mal, quando isto convier para a tranquilidade da sua alma, e a não ceder às tentações do inimigo na agonia da morte.

Os registros de óbitos em análise não deixam dúvidas sobre a importância dos sacramentos, pois a sua ausência aparece constantemente justificada nestes, como demonstra o excerto abaixo:

$<$ Francisco $\mid$ ezcravo > Aos vinte dias domes deAbril de mil sete centos e I ojtenta eSete faleçeu Francisco danaçaó angola, I Sem sacramentos por ter sido repentina amorte, cujocorpo l emcomendej, eSelhedeu sepultura no Adro desta $\mathrm{Ma}$ I tris deque para constar fis este termo eraut supra I $\underline{\mathrm{O} \text { Vigário AlexandreFerreira daRocha }}$ (Livro de Óbitos 1, fl. 5v.)

A grande quantidade de escravos, negros, crioulos, pardos ou mulatos, nos registros de óbitos da Matriz de Santa Luzia, correlaciona-se à expressiva leva de africanos traficados para o Brasil e utilizados como mão-de-obra nas atividades mais variadas, constituindo, indubitavelmente, a força motriz da economia colonial brasileira. O registro elencado acima dá mostras da condição de escravidão do morto, assim como a nação da qual ele procedia, a saber, a Angola.

Contudo, à esteira de Scherer, o conceito de nação deve ser considerado com ressalvas, uma vez que "nações africanas foram identidades políticas organizadas mais na experiência do cativeiro do que em uma origem comum na África" (2008, p. 195). Isso significa que nem sempre a nação atribuída ao negro no Brasil correspondia à sua real procedência africana. Muito antes, era uma característica definida pelo tráfico negreiro, que podia ou não representar a identidade étnica, cultural e linguística da maioria dos indivíduos rotulados por uma mesma nação. Assim, tal fato sinaliza para a sobreposição de uma identidade africana às características da nação específica à qual o indivíduo pertencia, que era aos poucos esquecida ou homogeneizada, conforme o autor (2008).

O que chama a atenção é o fato de que a escravidão não foi uma condição assumida pelos africanos em solo brasileiro, mas reproduzida nele, tendo em vista o que já se fazia na África. Prandi (2000, p. 53) afirma que o africano já era submetido ao cativeiro antes mesmo da descoberta da América, pelos europeus, embora tenha se tornado uma prática mais lucrativa para o próprio africano após o tráfico para esta.

Para se ter uma dimensão mais clara da numerosidade de africanos traficados para o Brasil e que foram também aqui submetidos a condições de trabalho desumanas, Prandi pontua que: 
Entre os anos de 1525 e 1851, mais de cinco milhões de africanos foram trazidos para o Brasil na condição de escravos, não estando incluídos neste número, que é uma aproximação, aqueles que morreram ainda em solo africano, vitimados pela violência da caça escravista, nem os que pereceram na travessia oceânica” (PRANDI, 2000, p. 52).

Como aponta o autor acima, o tráfico de africanos para serem empregados como mão-de-obra em diversos países e nações era visto por muitos africanos como um negócio vantajoso financeiramente, haja vista as condições precárias de vida de grande parte da população daquele país, o que desencadeou uma verdadeira "caça escravista”, nas palavras do próprio autor.

Ainda segundo Prandi (2000), esta prática não atingia apenas um povo ou nação africana, mas uma diversidade destes que, em terras brasileiras, foram submetidos ao Cristianismo. É o que se nota no registro acima, em que os sacramentos da penitência e extrema-unção foram ministrados ao falecido Francisco, diante da previsibilidade da sua morte. Além disso, havia a imposição do uso da língua portuguesa. Em contrapartida, os africanos deixaram marcas dos seus falares, das suas manifestações culturais e doutrinas religiosas na cultura brasileira, tornando-se constitutivas delas.

O fluxo do tráfico de escravos estava intimamente ligado à prosperidade econômica brasileira. Em Goiás, por exemplo, a mão-de-obra escrava se revelou mais intensa nas regiões de exploração aurífera, principal atividade econômica da região no período colonial.

É importante ressaltar que esta exposição traz apenas uma amostragem dos resultados da pesquisa realizada em nosso estágio pós-doutoral, que se encontra em andamento, a qual já aponta para questões significativas sobre o cenário sociocultural e histórico da escravidão africana na Capitania goiana.

\section{CONSIDERAC̣ÕES FINAIS}

O texto demonstra que as pesquisas por nós realizadas até o momento têm a mesma orientação teórico-metodológica, isto é, envolveram a edição semidiplomática e o estudo lexical de documentos goianos do século XVIII ao XX, em sua intersecção com a História e a cultura goiana. Foi possível perceber também a importância da Lexicografia para as investigações feitas, fornecendo o aparato necessário para que a análise lexical se fizesse de maneira mais clara e eficaz. 
Ensejamos, com o presente texto, incitar pesquisas temáticas da filologia e do léxico goiano, a fim de intensificar o diálogo com grupos de pesquisa destas linhas de pesquisa distribuídos por regiões distintas do país, como São Paulo, Bahia, Rio de Janeiro, Belo Horizonte, Mato Grosso do Sul etc., contribuindo, desta maneira, com a história do português brasileiro.

É importante salientar que as pesquisas aqui abordadas não se restringem ao âmbito da Filologia e da Lexicologia, mas contribuem com os estudos linguísticos de modo geral, além de interessar a disciplinas afins, como a História. Assim, o diálogo entre áreas distintas do saber tem se mostrado cada vez mais frutífero nos estudos lexicais da língua, quando não um imperativo do próprio objeto de investigação. Esta conjunção de perspectivas resulta de um esforço de abordar de maneira ampla os textos manuscritos de séculos passados, no intuito de evidenciar de que modo a cultura e a sociedade neles se revelam através de teias de formas e sentidos lexicais, tendo a Filologia como fonte e fim dos textos manuscritos.

Assim, o fato de as pesquisas abarcarem localidades diferentes do território goiano, a saber, a cidade de Catalão, Vila Boa de Goiás e Santa Luzia, assim como espécies documentais variadas, vale dizer, o termo de praça, a carta e o registro de óbito, indicam olhares múltiplos sobre o léxico e sobre a cultura goiana ao longo de sua história, bem como sobre os seus documentos. 


\section{Title: LEXICAL-CULTURAL ASPECTS IN MANUSCRIPTS OF GOIÁS: routes of research}

\section{Abstract}

This paper aims to revisit our research experiences, from undergraduate course to post-doctorate, aiming to demonstrate the theoretical-methodological convergence between them. In this direction, it must be said that the three researches conducted until now; a scientific initiation research, a doctorate, and the current post-doctorate, have in common that they are supported by the semidiplomatic edition of manuscripts of Goiás, in order to inventory the lexicon and analyze it in relation with the History and culture of Goiás. The first edited documents were "termos de praça" of the town of Catalão, that date back to the early decades of the XX Century. The second documents were mostly letters exchanged between the Governor of the Captaincy of Goiás and King D. José I and dated back to town of Vila Boa de Goiás in the XVIII Century; the latter are death records of the town of Santa Luzia de Goiás, from 1786 to 1789. Despite these dissonances, the researches converge in the thematic area, is important to say, the intersection between the lexical studies and sociocultural aspects, in different nuances, in the processing of data, based in philological and lexical perspectives and in documentary material of Goiás.

Keywords: Lexicon; Culture of Goiás; Philology. 


\section{REFERÊNCIAS}

$2^{\circ}$. Livro dos registros de termos de praça da Intendencia Municipal de Catalão. Museu Municipal Cornélio Ramos. Acervo Público Municipal de Catalão, registro PMC APM S ADM 1902-005.

BLUTEAU, Raphael. Vocabulario portuguez \& latino. Coimbra: Collegio das Artes da Companhia de Jesus, 1712-1728.

CALDAS AULETE, Francisco Júlio. Diccionario Contemporâneo da Língua Portugueza. Lisboa: Livraria Editora, 1881.

CÂMARA, Tania Maria Nunes de Lima. Léxico e conhecimento de mundo. Revista Philologus, Rio de Janeiro, ano 16, n. 46, p. 46-54, jan./abr., 2010.

DUBOIS, Jean et al. Dicionário de Lingǘstica. São Paulo: Cultrix, 1997.

FERREIRA, Aurélio Buarque de Holanda. Novo dicionário eletrônico Aurélio. 3. ed. Positivo, 2004.

FIGUEIREDO, Cândido. Novo dicionário da língua portuguesa. 6. ed. Lisboa; Rio de Janeiro: Livraria Bertrand/W. M. Jackson Inc., 1925.

HARRIS, William. Um réquiem para a filologia? Será que é tarde demais? Nunca foi importante? Revista Philologus, Rio de Janeiro, ano 12, n. 35, p. 134-143, 2006.

HOUAISS, Antônio; VILLAR, Mário Silva. Dicionário Houaiss da língua portuguesa. Rio de Janeiro: Objetiva, 2001. LACET, Juliana Lemos. Os rituais de morte nas irmandades de escravos e libertos: Vila Rica, século XVIII. 2003. 53f. Monografia (Bacharelado em História) - Universidade Federal de Ouro Preto, Mariana.

Livro para servir no registro do caminho novo de Parati - Thomé Ignácio da Costa Mascarenhas (1724-1762). Arquivo Histórico Estadual de Goiás. 1724-1762. fólios 66-139.

MORAES SILVA, Antonio. Diccionario da língua portugueza. 2. ed. Lisboa: Typographia Lacérdina, 1813.

NOGUEIRA, Wilson Cavalcante. Mestre carreiro. In: A foldórica. Goiânia-Go: Instituto Goiano do Foldore da Fundação Cultural de Goiás, 1980. vol. 8.

Óbitos Livro 01 1786-1814. Paróquia de Luziânia-G0. 1786-1814. fólios 1-32.

ORTÊNCIO, Waldomiro Bariani. Dicionário do Brasil Central: subsídios à Filologia. São Paulo: Ática, 1983.

PRANDI, Reginaldo. De africano a afro-brasileiro: etnia, identidade, religião. Revista USP, São Paulo, n. 46, p. 52-65, jun./ago, 2000.

SCHERER, Jovani de Souza. Parentesco de nação: vestígios de uma Comunidade Africana em Rio Grande. Anos 90, Porto Alegre, v. 15, n. 27, p. 189-231, jul., 2008.

XAVIER, Vanessa Regina Duarte. Conexões léxico-culturais sobre as minas goianas setecentistas no Livro para Servir no registro do caminho novo de Parati. 2012. 580f. Tese (Doutorado em Letras) - Faculdade de Filosofia, Letras e Ciências Humanas, Universidade de São Paulo, São Paulo.

. Tramas lexicais e culturais em manuscrito goiano: notas para a composição de um Glossário. 2008.

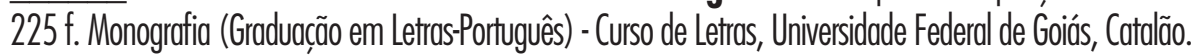

